\title{
Modification of an erodibility category limit for the pocket erodometer
}

\author{
Reza Rahimnejad and Phillip S.K. Ooi \\ University of Hawaii, Honolulu, HI, USA
}

\begin{abstract}
The pocket erodometer test (PET) is an inexpensive and expedient way to derive the erosion categories of soils. The test involves impinging a regulated jet of water at the end of an undisturbed soil sample and measuring the depth of scoured hole after 20 jet applications. The depth of the scoured hole provides an indication of the erosion category. PET and companion erosion function apparatus (EFA) tests were performed on 33 cohesive soil samples from 5 different sites on the island of Oahu, Hawaii. In the EFA test, water is run over a Shelby tube of soil placed at the bottom of a flume. The rate of scour is measured under different flow velocities. PET and EFA tests data were used to develop a plot of the PET erosion depth versus EFA erosion category which revealed that a correlation clearly exists between PET erosion depth and EFA erosion category value, the PET erosion depth that separates medium and high erodibility categories should be revised and the erodibility criteria based on soil classification is not very reliable for Hawaiian fine-grained soils.
\end{abstract}

\section{INTRODUCTION}

Developed by Briaud et al. (2012), the pocket erodometer test (PET) is an inexpensive and expedient way to derive the erosion categories for soils. The test involves impinging a regulated jet of water at the end of an undisturbed soil sample and measuring the depth of scoured hole after 20 jet applications. The depth of the scoured hole provides an indication of the erosion category (varying from very high to high to medium to low to very low erodibility) of a soil as shown in Figure 1. The current range of PET depths of scoured hole for the erosion categories of medium and high erodibility are between 1 and $15 \mathrm{~mm}$ and 15 and $75 \mathrm{~mm}$, respectively. Briaud et al. (2012) established these limits based on 28 data points but no data was available between depths of scoured hole of 19 and $72 \mathrm{~mm}$. In Figure 1, Briaud et al. (2012) also correlated the erosion categories with soil classification based on the Unified Soil Classification System.

PET and companion erosion function apparatus (EFA) tests were performed on 33 cohesive soil samples from 5 different sites on the island of Oahu, Hawaii. In the EFA test, water is run over a Shelby tube of soil placed at the bottom of a flume. The rate of scour (i.e., the rate at which the soil is pushed upwards and washed away) is measured under dif- ferent flow velocities. According to Briaud et al. (2012), the last two points of the EFA test provide a good estimate of the erosion category of the soil and is used as the basis for comparison to the PETderived erodibility category.

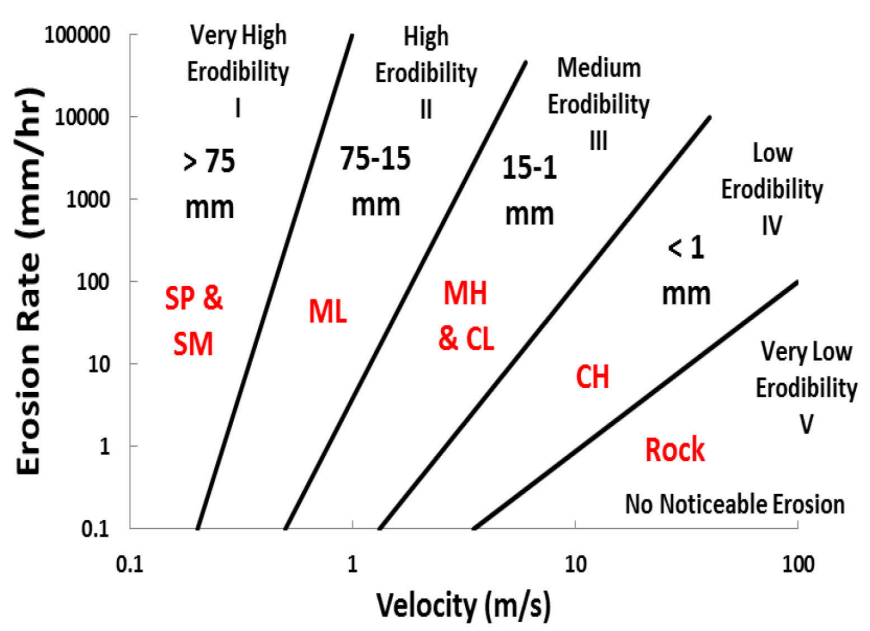

Figure 1. PET erosion depth ranges and the corresponding erosion categories (after Briaud et al. 2012).

With the aid of the PET and EFA test results, the objectives of this study are to: (1) examine the reliability of the PET-derived erosion categories proposed by Briaud et al. (2012); (2) propose changes to 
the erosion category limits if applicable; and (3) examine the reliability of the erosion categories based on soil classification as proposed by Briaud et al. (2012).

\section{SOILS TESTED}

PET and EFA tests were conducted on 33 different cohesive soil samples collected from 5 different water crossings located on the island of Oahu, Hawaii. A plan of the sites is shown in Figure 2. Four of the sites lie on the south side of the island with the samples retrieved from a relatively impermeable layer (termed the "caprock" which is truly a misnomer because it is not a rock) overlying a basalt aquifer. $\mathrm{Ob}$ tained from northeast Oahu, the location of the fifth site was chosen for wider geographic coverage. Pertinent details of these soils are summarized in Table 1 .

Hydrometer testing was used to estimate the \% finer than $2 \mu$ and the median grain size or $D_{50}$. Undrained shear strengths were measured using unconsolidated undrained triaxial tests performed in ac- cordance with American Society of Testing and Materials Standards ASTM D2850.

Prior to PET testing, the pocket erodometer was calibrated as described below.

\section{CALIBRATION OF THE POCKET ERODOMETER}

The PET is a water pistol (Figure 3) aimed at the vertical face of a soil placed at a horizontal distance of $50 \mathrm{~mm}$ away (Briaud et al., 2012). It has a nozzle diameter of approximately $0.5 \mathrm{~mm}$ and prior to use, it was calibrated to have a nozzle velocity of about 8 $\mathrm{m} / \mathrm{s}$ in accordance with the procedure outlined by Briaud et al. (2012). Undisturbed soil samples are subjected to 20 jet applications at a rate of 1 jet per second. PET tests were conducted at a minimum of 3 different locations on the face of the soil sample and the PET erosion depth is taken as the average depth of penetration.

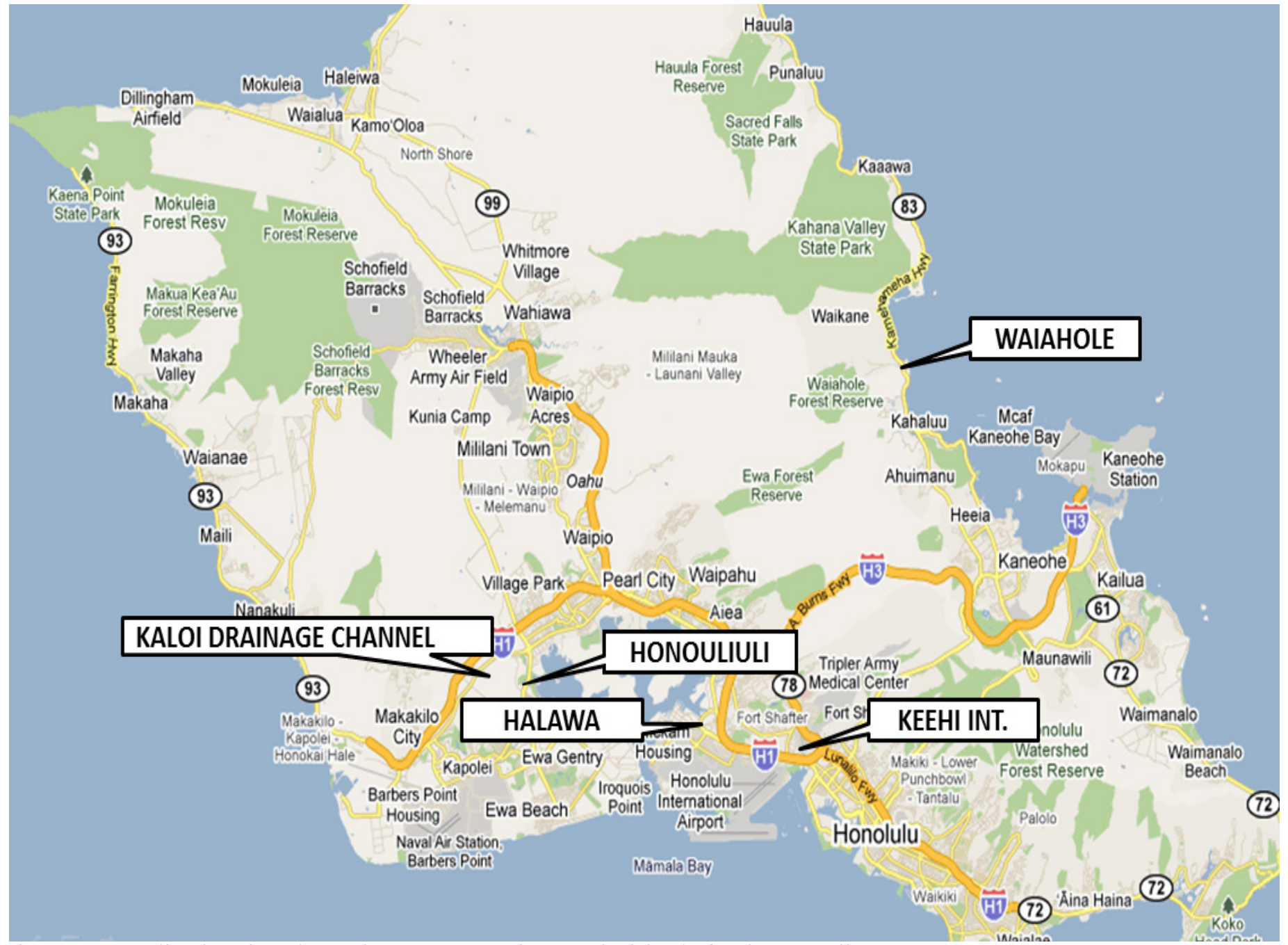

Figure 2. Sampling location plan at the 5 water crossings on the island of Oahu, Hawaii. 
Table 1. Summary of cohesive soil samples and properties subjected to PET and EFA testing.

\begin{tabular}{|c|c|c|c|c|c|c|c|c|}
\hline Location & Sample Number & $\begin{array}{c}\text { Sample } \\
\text { Depth } \\
(\mathrm{m})\end{array}$ & $\begin{array}{c}\text { USCS Soil } \\
\text { Classification }\end{array}$ & $\begin{array}{c}\begin{array}{c}\text { Water } \\
\text { Content }\end{array} \\
(\%) \\
\end{array}$ & $\begin{array}{c}\% \\
\text { Fines }\end{array}$ & $\begin{array}{c}\% \\
< \\
2 \mu\end{array}$ & $(\mathrm{mm})$ & $\begin{array}{l}\text { Undrained } \\
\text { Shear } \\
\text { Strength } \\
(\mathrm{kPa}) \\
\end{array}$ \\
\hline \multirow{4}{*}{$\begin{array}{l}\text { Waiahole } \\
\text { Stream }\end{array}$} & B-2/SH6 & 6.86 & MH & 62 & 63 & 11 & 0.033 & 29 \\
\hline & B-2/SH8 & 8.38 & MH & 72 & 99 & 34 & 0.008 & 28 \\
\hline & B-2/SH10 & 9.91 & MH & 68 & 51 & 10 & 0.007 & 34 \\
\hline & B-2/SH14 & 12.7 & MH & 53 & 99 & 35 & 0.006 & - \\
\hline \multirow{6}{*}{$\begin{array}{l}\text { Honouliuli } \\
\text { Stream }\end{array}$} & B-3A/SH3 & 2.06 & $\mathrm{MH}$ & 64 & 82 & 24 & 0.020 & 18 \\
\hline & B-3A/SH9 & 7.09 & MH & 62 & 79 & 20 & 0.013 & 13 \\
\hline & B-3A/SH11 & 8.61 & ML & 69 & 83 & 23 & 0.008 & 16 \\
\hline & B-3B/SH1 & 2.51 & MH & 56 & 55 & 18 & 0.053 & 20 \\
\hline & B-3B/SH3 & 5.56 & MH & 72 & 74 & 25 & 0.014 & 25 \\
\hline & B-3B/SH4 & 7.09 & $\mathrm{MH}$ & 78 & 73 & 13 & 0.038 & 18 \\
\hline \multirow{7}{*}{$\begin{array}{l}\text { Moanalua } \\
\text { Stream }\end{array}$} & B-4B/SH1 & 3.43 & $\mathrm{CH}$ & 67 & 99 & 58 & 0.0011 & 11 \\
\hline & B-4B/SH3 & 4.95 & MH & 89 & 98 & 53 & 0.0014 & 16 \\
\hline & B-4B/SH5 & 6.48 & MH & 77 & 99 & 43 & 0.0040 & 16 \\
\hline & B-4B/SH7 & 8.00 & MH & 72 & 97 & 35 & 0.0055 & 21 \\
\hline & B-4B/SH9 & 9.53 & MH & 74 & 96 & 41 & 0.0045 & 18 \\
\hline & B-4B/SH11 & 11.0 & MH & 66 & 99 & 31 & 0.0061 & 23 \\
\hline & B-4B/SH13 & 12.6 & MH & 68 & 99 & 47 & 0.0028 & 21 \\
\hline \multirow{7}{*}{$\begin{array}{l}\text { Kaloi Drain- } \\
\text { age Channel }^{1}\end{array}$} & B-6/SH2 & 3.89 & $\mathrm{CH}$ & 26 & 100 & 68 & 0.0002 & 371 \\
\hline & B-6/SH6 & 6.55 & ML & 23 & 98 & 30 & 0.0090 & 303 \\
\hline & B-6/SH9 & 8.15 & $\mathrm{CL}$ & 24 & 100 & 32 & 0.0070 & 149 \\
\hline & B-6/SH11 & 9.25 & ML & 22 & 98 & 36 & 0.0060 & 507 \\
\hline & B-6/SH17 & 13.0 & ML & 22 & 82 & 11 & 0.0205 & 407 \\
\hline & B-6/SH19 & 14.2 & ML & 36 & 61 & 15 & 0.0230 & 230 \\
\hline & B-6/SH23 & 16.5 & ML & 23 & 99 & 33 & 0.0080 & 268 \\
\hline \multirow{9}{*}{$\begin{array}{l}\text { Halawa } \\
\text { Stream }\end{array}$} & B-7/SH1 & 4.57 & MH & 73 & 97 & 39 & 0.0036 & 29 \\
\hline & B-7/SH5 & 8.08 & MH & 50 & 67 & 16 & 0.0270 & 48 \\
\hline & B-7/SH7 & 9.60 & MH & 85 & 89 & 21 & 0.0110 & 57 \\
\hline & B-7/SH9 & 11.1 & MH & 57 & 93 & 20 & 0.0090 & 57 \\
\hline & B-7/SH11 & 12.6 & MH & 77 & 93 & 26 & 0.0080 & 55 \\
\hline & B-7/SH13 & 14.2 & MH & 76 & 98 & 30 & 0.0100 & 59 \\
\hline & B-7/SH15 & 15.7 & MH & 71 & 98 & 34 & 0.0095 & - \\
\hline & B-7/SH17 & 17.2 & MH & 65 & 98 & 24 & 0.0110 & 52 \\
\hline & B-7/SH19 & 18.7 & MH & 74 & 99 & 27 & 0.0095 & 25 \\
\hline
\end{tabular}

Note: 1. Kaloi Drainage Channel is dry most of the time. Hence, soil is desiccated with high shear strengths. Undisturbed samples were retrieved using a Pitcher sampler at this location. Shelby tubes were used at the other 4 streams.

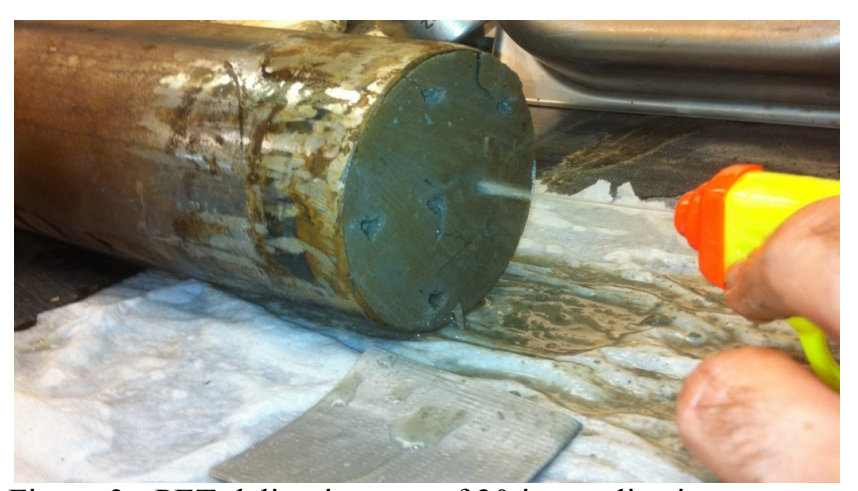

Figure 3. PET delivering one of 20 jet applications at a rate of 1 jet per second.

\section{CALIBRATION OF THE EFA AND INTERPRETATION OF EROSION CATEGORIES}

Prior to EFA testing, the flowmeter was calibrated to ensure that the flow and hence flow velocities are accurate. Each EFA test yielded between 4 and 7 data points as shown in Table 2.

Briaud et al. (2012) presented 4 different methods for interpreting the erosion categories of soils. In the first method, all the points from an EFA test are plotted on a chart similar to Figure 1. The erosion category of the soil is the one that contains the most number of data points. In the second method, a regression line is drawn through the EFA data points plotted on a chart similar to Figure 1. The erosion category is the one that contains the mid-point of the regression line. In the third method, the first and last points of the EFA test data are plotted on a chart similar to Figure 1. The erosion categories are esti- 
mated for these two points and the erosion category is taken as the average of these two values. Their recommended method of interpretation is the fourth method, which is to use the average of the last two points of the EFA test. They indicated that this method provides the best estimate of the erosion category because the last two points represent the highest velocities, which are most relevant and appropriate for classifying the erosion categories

Despite the fact that the scour mechanism is different in the PET and EFA tests (water impinges horizontally onto a vertical soil surface in the PET whereas water flows parallel to a horizontal soil surface in the EFA), there is a strong correlation between the PET and EFA erosion categories as discussed below.

\section{TEST RESULTS}

The measured PET erosion depths are summarized in the fifth column of Table 2. Seventeen of the 33 tests had erosion depths between 19 and $54 \mathrm{~mm}$, which were helpful for populating the gap in data missing from Briaud et al.'s (2012) study (no data was available between depths of scoured hole of 19 and $72 \mathrm{~mm}$ in their study).

The erosion categories were also discerned using EFA test results based on Briaud et al.'s (2012) Method 4 described earlier. These are shown on the fourth column of Table 2 . The precision of the values in the fourth column was enhanced by dividing the erosion categories into 10 smaller sub-categories as shown in Figure 4. If a dashed line drawn through the middle of each category is considered to be the number for that category, then the category limit lines (thick solid lines) drawn in figures 1 and 4 represent \pm 0.5 of that number. For example, a soil in Category 2 can have an erosion category value (ECV) such that $1.5 \leq \mathrm{ECV}<2.5$. By plotting the average of the last two points of the EFA test in Figure 4, the EFA ECV can be attained as shown in Column 4 of Table 2. If the EFA ECV is considered the "correct" value with which the PET erosion category can be compared to, then the PET erosion category predicts the correct erodibility 24 times out of the 33 tests ( $73 \%$ accuracy).

To study the reliability of the PET erodibility prediction capability, the PET erosion depth is replotted versus the EFA ECV in Figure 5. Figure 5 reveals that: (1) a correlation $\left(\mathrm{R}^{2}=0.75\right)$ clearly exists between PET erosion depth and EFA ECV for the Hawaii data; (2) the reliability of the method can be improved by increasing the PET erosion depth that separates the medium and high erodibility categories from $15 \mathrm{~mm}$ to $28 \mathrm{~mm}$. Alternatively, the category limit lines could be curved but this alternative is not explored in the interest of maintaining the original look of the charts; and (3) with this revised criterion, only one of the 33 PET tests from this research provide the wrong erosion category ( $97 \%$ accuracy).

In Figure 5, the original data used by Briaud et al. (2012) to derive the erosion categories are also plotted as circles. It can be seen that there is an improvement in the precision with their data as well as the number of errors reduced from 4 to 3 with this proposed change. Therefore, the proposed PET erosion depth limits for medium and high erodibility of 1 and $28 \mathrm{~mm}$ and 28 and $75 \mathrm{~mm}$, respectively not only improves the reliability of the PET for Hawaii soils but also the reliability of the PET for the soils used in the original development of this criterion.

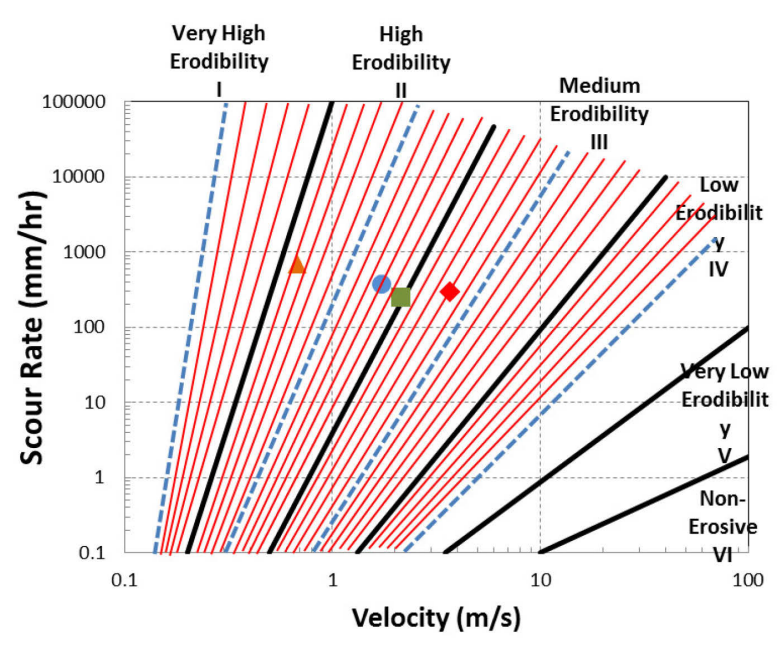

- B2-SH6 $\quad$ B $2-$ SH8 $\quad$ B B2-SH10 B2-SH14

Figure 4. More precise derivation of EFA erosion categories for soils from Waiahole (Boring B2).

\section{DIFFERENCES BETWEEN BRIAUD ET AL.'S (2012) SOILS AND SOILS FROM THIS STUDY}

The two data-sets plotted in Figure 5 look different, with the tests from this study showing distinctly more erosion depth compared with Briaud et al.'s (2012) data for the same erosion category. Also, Briaud et al.'s data look uncorrelated to erosion category. Possible explanations may be attributed to two fundamental differences between Briaud et al.'s data and data from this study as follows: 
Table 2. Summary of PET and EFA erosion categories.

\begin{tabular}{|c|c|c|c|c|c|c|c|c|}
\hline Location & $\begin{array}{l}\text { Sample } \\
\text { Number }\end{array}$ & $\begin{array}{c}\text { Number } \\
\text { of EFA } \\
\text { Data } \\
\text { Points }\end{array}$ & $\begin{array}{c}\text { EFA } \\
\text { Erosion } \\
\text { Category }\end{array}$ & $\begin{array}{c}\text { PET } \\
\text { Erosion } \\
\text { Depth } \\
(\mathrm{mm})\end{array}$ & $\begin{array}{c}\text { PET } \\
\text { Erosion } \\
\text { Category }\end{array}$ & $\begin{array}{c}\text { PET Ac- } \\
\text { curacy }\end{array}$ & $\begin{array}{c}\text { USCS } \\
\text { Erosion } \\
\text { Category }\end{array}$ & $\begin{array}{c}\text { USCS } \\
\text { Accuracy }\end{array}$ \\
\hline & B-2/SH6 & 4 & 2.3 & 39 & 2 & $\sqrt{ }$ & 3 & $\mathrm{x}$ \\
\hline Waiahole & B-2/SH8 & 4 & 2.4 & 23 & 2 & $\sqrt{ }$ & 3 & $\mathrm{x}$ \\
\hline Stream & B-2/SH10 & 4 & 1.6 & 54 & 2 & $\sqrt{ }$ & 3 & $\mathrm{x}$ \\
\hline & B-2/SH14 & 4 & 2.8 & 9 & 3 & $\sqrt{ }$ & 3 & $\sqrt{ }$ \\
\hline & B-3A/SH3 & 5 & 2.5 & 26 & 2 & $\mathrm{x}$ & 3 & $\sqrt{ }$ \\
\hline & B-3A/SH9 & 5 & 2.2 & 45 & 2 & $\sqrt{ }$ & 3 & $\mathrm{x}$ \\
\hline Honouliuli & B-3A/SH11 & 4 & 2.2 & 28 & 2 & $\sqrt{ }$ & 2 & $\sqrt{ }$ \\
\hline Stream & B-3B/SH1 & 4 & 2.7 & 26 & 2 & $\mathrm{x}$ & 3 & $\sqrt{ }$ \\
\hline & $\mathrm{B}-3 \mathrm{~B} / \mathrm{SH} 3$ & 5 & 2.4 & 39 & 2 & $\sqrt{ }$ & 3 & $\mathrm{x}$ \\
\hline & B-3B/SH4 & 4 & 2.4 & 35 & 2 & $\sqrt{ }$ & 3 & $\mathrm{x}$ \\
\hline & B-4B/SH1 & 4 & 2.4 & 28 & 2 & $\sqrt{ }$ & 4 & $\mathrm{x}$ \\
\hline & $\mathrm{B}-4 \mathrm{~B} / \mathrm{SH} 3$ & 4 & 2.7 & 14 & 3 & $\sqrt{ }$ & 3 & $\sqrt{ }$ \\
\hline Moanalu & B-4B/SH5 & 7 & 2.7 & 15 & 3 & $\sqrt{ }$ & 3 & $\sqrt{ }$ \\
\hline Noanaila & B-4B/SH7 & 5 & 2.6 & 24 & 2 & $\mathrm{x}$ & 3 & $\sqrt{ }$ \\
\hline stream & B-4B/SH9 & 5 & 2.8 & 24 & 2 & $\mathrm{x}$ & 3 & $\sqrt{ }$ \\
\hline & B-4B/SH11 & 4 & 2.8 & 9 & 3 & $\sqrt{ }$ & 3 & $\sqrt{ }$ \\
\hline & B-4B/SH13 & 4 & 2.7 & 19 & 2 & $\mathrm{x}$ & 3 & $\sqrt{ }$ \\
\hline & B-6/SH2 & 4 & 2.9 & 7 & 3 & $\sqrt{ }$ & 4 & $\mathrm{x}$ \\
\hline & B-6/SH6 & 4 & 2.7 & 6 & 3 & $\sqrt{ }$ & 2 & $\mathrm{x}$ \\
\hline Kaloi & B-6/SH9 & 7 & 2.7 & 6 & 3 & $\sqrt{ }$ & 3 & $\sqrt{ }$ \\
\hline Drainage & B-6/SH11 & 6 & 2.8 & 6 & 3 & $\sqrt{ }$ & 2 & $\mathrm{x}$ \\
\hline Channel $^{1}$ & B-6/SH17 & 6 & 2.8 & 4 & 3 & $\sqrt{ }$ & 2 & $\mathrm{x}$ \\
\hline & B-6/SH19 & 4 & 2.9 & 4 & 3 & $\sqrt{ }$ & 2 & $\mathrm{x}$ \\
\hline & B-6/SH23 & 7 & 2.6 & 7 & 3 & $\sqrt{ }$ & 2 & $\mathrm{x}$ \\
\hline & B-7/SH1 & 5 & 2.8 & 9 & 3 & $\sqrt{ }$ & 3 & $\sqrt{ }$ \\
\hline & B-7/SH5 & 6 & 2.4 & 28 & 2 & $\sqrt{ }$ & 3 & $\mathrm{x}$ \\
\hline & B-7/SH7 & 7 & 2.6 & 18 & 2 & $\mathrm{x}$ & 3 & $\sqrt{ }$ \\
\hline & B-7/SH9 & 7 & 2.6 & 25 & 2 & $\mathrm{x}$ & 3 & $\sqrt{ }$ \\
\hline Halawa & B-7/SH11 & 6 & 2.8 & 11 & 3 & $\sqrt{ }$ & 3 & $\sqrt{ }$ \\
\hline Stream & B-7/SH13 & 7 & 2.8 & 12 & 3 & $\sqrt{ }$ & 3 & $\sqrt{ }$ \\
\hline & B-7/SH15 & 5 & 2.9 & 19 & 2 & $\mathrm{x}$ & 3 & $\sqrt{ }$ \\
\hline & B-7/SH17 & 6 & 2.8 & 8 & 3 & $\sqrt{ }$ & 3 & $\sqrt{ }$ \\
\hline & B-7/SH19 & 4 & 2.7 & 20 & 2 & $\mathrm{x}$ & 3 & $\sqrt{ }$ \\
\hline & & & \multicolumn{3}{|c|}{ No. Correct/Total No. } & $24 / 33$ & & $19 / 33$ \\
\hline & & & \multicolumn{3}{|c|}{$\%$ Correct } & $73 \%$ & & $58 \%$ \\
\hline
\end{tabular}

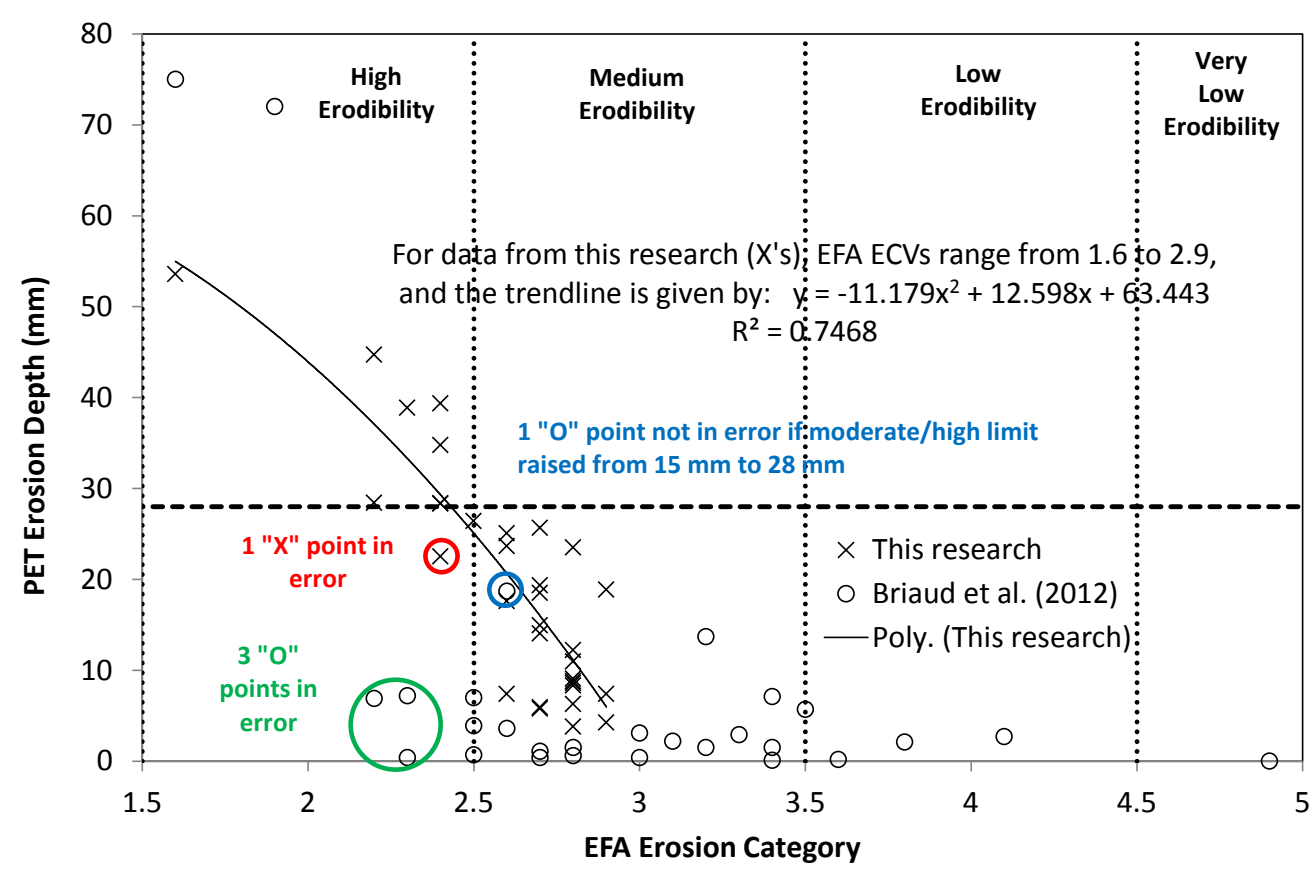

Figure 5. Pocket erodometer test erosion depth versus EFA erosion category value from this research (X's in plot) and from Briaud et al. (2012) (O's in plot). Note if moderate/high limit is raised from 15 to $28 \mathrm{~mm}$, only 1 " $\mathrm{X}$ " and 3 "O" points are in error. 
1. The soils in this study are predominantly silts while the soils from Briaud et al.'s (2012) study were mostly clays (Figure 6). According to USDA (1990), clayey soils are more resistant against erosion than silts. Also, the percent $<2 \mu$ (or percent clay according to some soil classification systems) for soils in this study average $30 \%$ and range from $10 \%$ to $68 \%$ while those from Briaud et al.'s (2012) study average 35\% and range from $16 \%$ to $100 \%$.

2 . The soils in this study have higher water contents (average $=60 \%$ with a range varying from $22 \%$ to $89 \%$ ) than those from Briaud et al.'s (2012) study (average $=26 \%$ with a range varying from $3 \%$ to $45 \%$ ). As water content increases in a saturated soil, the shear strength decreases, the critical shear stress decreases (Rahimnejad and Ooi, 2016) and the erosion rate increases.

In summary, the soils from this study have larger erosion depths because they are silts rather than clays and they have higher water contents.

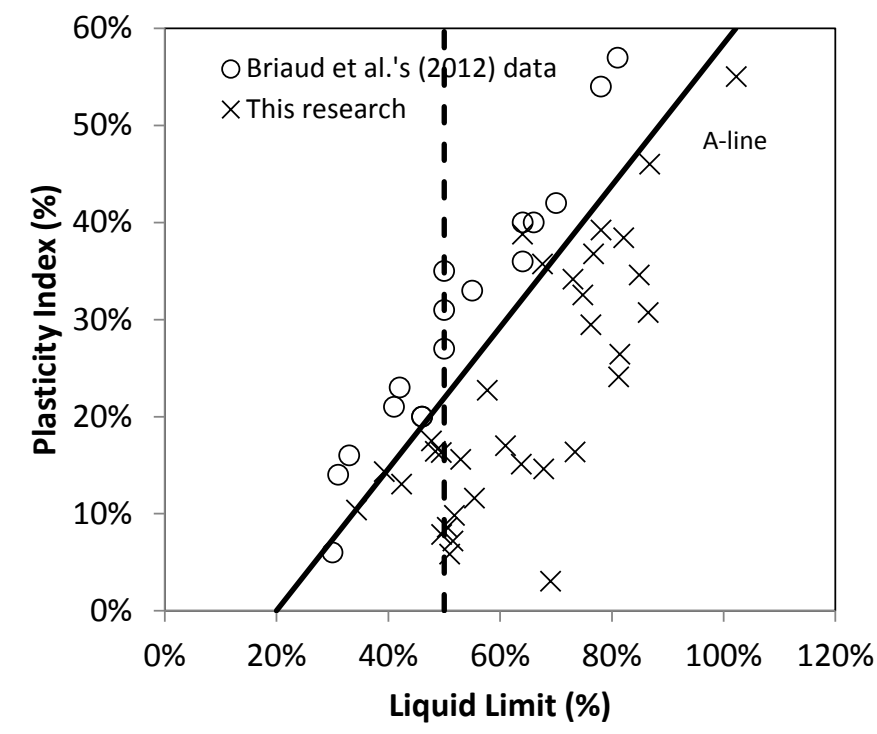

Figure 6. Plasticity characteristics of soils from this study and from Briaud et al. (2012).

\section{USCS CLASSIFICATION AND EFA TEST RESULTS}

Using Briaud et al.'s (2012) erodibility criteria based on soil classification as shown in Figure 1, of the 33 tests conducted in this research, 19 erosion categories were correct (58\% accuracy) when compared to the EFA ECVs (Table 2). This suggests that the erodibility criteria based on soil classification is not very reliable for Hawaiian fine-grained soils.

\section{SUMMARY AND CONCLUSIONS}

PET and companion EFA tests were performed on 33 cohesive soil samples from 5 different sites on the island of Oahu, Hawaii. The PET erosion depths were used to derive the erosion categories, which were then compared to those using the EFA. If the EFA ECV is considered the "correct" value with which the PET erosion category can be compared to, then the PET erosion depth provides the correct erodibility 24 times out of the 33 tests (73\% accuracy).

To study the reliability of the PET prediction capability, the PET erosion depth was plotted versus the EFA ECV. This plot revealed that: (1) a correlation $\left(\mathrm{R}^{2}=0.75\right)$ clearly exists between PET erosion depth and EFA ECV; (2) the PET erosion depth of $15 \mathrm{~mm}$ that separates the medium and high erodibility categories should be increased to $28 \mathrm{~mm}$ to increase the reliability of the method; and (3) with this revised criterion, only one of the 33 PET tests from this research provides the wrong erosion category (97\% accuracy). The proposed PET erosion depth limits for medium and high erodibility of 1 and 28 $\mathrm{mm}$ and 28 and $75 \mathrm{~mm}$, respectively not only improves the reliability of the PET for Hawaii soils but also the reliability of the PET for the soils used in the original development of this criterion. The reason why the soils from this study have larger erosion depths is because they are silts rather than clays and they have higher water contents.

When assessing the applicability of Briaud et al.'s (2012) erodibility criteria based on soil classification, of the 33 tests, 19 erosion categories were correct when compared to the EFA ECVs (58\% accuracy). This suggests that the erodibility criteria based on soil classification is not very reliable for Hawaiian fine-grained soils.

\section{ACKNOWLEDGEMENTS}

The financial support of the State of Hawaii Department of Transportation (HDOT) in cooperation with the Federal Highway Administration (FHWA) is greatly appreciated and acknowledged. The contents of this paper reflect the view of the authors, who are responsible for the facts and accuracy of the data presented. The contents do not necessarily reflect the official views or policies of HDOT or FHWA. The contents contained herein do not constitute a standard, specification or regulation 


\section{REFERENCES}

Briaud, J.L., Bernhardt, M. and Leclair, M. (2012). The pocket erodometer test: Development and Preliminary Results. Geotechnical Testing Journal, Vol. 35, No. 2, pp. 342-352.

Rahimnejad, R. and Ooi, P.S.K. (2016). Factors affecting the critical shear stress of scour of cohesive soil beds. Transportation Research Record, Journal of the Transportation Research Board.

United States Department of Agriculture (1990). Engineering Field Handbook. United States Department of Agriculture. 